\title{
Relações hídricas, rendimento e compostos fenólicos de uvas Cabernet Sauvignon em três tipos de solo
}

\author{
Geraldo Chavarria $\left({ }^{1 *}\right)$; Homero Bergamaschi (2); Leonardo Cury da Silva (2); \\ Henrique Pessoa dos Santos ( $\left.{ }^{3}\right)$; Francisco Mandelli (3); Celito Crivellaro Guerra (3); \\ Carlos Alberto Flores $\left({ }^{4}\right)$; Jorge Tonietto $\left({ }^{3}\right)$ \\ (1) Universidade de Passo Fundo, Campus I, Caixa Postal 611, 99001-970 Passo Fundo (RS). \\ (2) Universidade Federal do Rio Grande do Sul, Departamento de Horticultura e Silvicultura, Avenida Bento Gonçalves, 7712 , \\ 91501-970 Porto Alegre (RS). \\ (3) Embrapa Uva e Vinho, Rua Livramento, 515, 95700-000 Bento Gonçalves (RS). \\ (4) Embrapa Clima Temperado, BR 392, km 78, Caixa Postal 403, 96010-971 Pelotas (RS). \\ (*) Autor correspondente: geraldochavarria@upf.br
}

Recebido: 19/mai./2010; Aceito: 29/jul./2010.

\section{Resumo}

No presente trabalho, foi avaliada a influência de três tipos de solo (Argissolo Bruno-acizentado, Planossolo Háplico e Neossolo Regolítico) sobre aspectos quantitativos e qualitativos da produção de uvas destinadas à vinificação. O experimento foi executado no ciclo 2008/2009, em vinhedo da cultivar Cabernet Sauvignon (Vitis vinifera L.), no município de Bento Gonçalves, (RS). Avaliou-se a disponibilidade hídrica em base gravimétrica ao longo do período de maturação das uvas, o potencial da água na folha, parâmetros de crescimento vegetativo, componentes do rendimento e os compostos fenólicos no momento da colheita. Argissolos Bruno-acizentados propiciaram maior crescimento vegetativo, sobretudo em massa de ramos, comprimento de entrenós e área foliar, assim como, cachos com maior número de bagas. Planossolos Háplicos com maior disponibilidade hídrica proporcionaram maior produtividade das videiras. Neossolos Regolíticos levaram à menor disponibilidade hídrica, o que reflete em redução do potencial da água na folha. Nestas condições de restrição hídrica, as videiras tiveram menor crescimento e rendimento, como também, maiores teores de taninos e índice de polifenóis totais. Em geral, o Neossolo Regolítico pode ser considerado mais promissor para a obtenção de vinhos finos de qualidade.

Palavras-chave: potencial da água na folha, produtividade, qualidade enológica, identidade enológica.

\section{Water relations, yield and phenolic compounds of grapevines cv. Cabernet Sauvignon in three soil types}

\footnotetext{
Abstract

Water conditions, influenced also by the soil type, determine the vegetative growth and plant development and have important effects on wine quality. In the present study, the influence of three soil types (Grayish Brown Argisol, Haplic Planosol and Regolitic Neosol) on quantitative and qualitative traits of grape production and vinification. The experiment was performed in the 2008/2009 season in vineyard of Cabernet Sauvignon cultivar (Vitis vinifera L.), in Bento Gonçalves, Brazil. The soil water availability (gravimetric basis) at ripening, leaf water potential, plant growth, yield components and phenolic compounds were evaluated. As compared to the Regolitic Neosol, the Grayish Brown Argisol caused higher vegetative growth, mainly in branch mass, length of internodes and leaf area, as well as promoted clusters with more berries. Haplic Planosols provided the highest water availability, causing high grape yield. There was lower water availability in Regolitic Neosols, which lead to decreases in leaf water potential. In this stressful condition the grapevines had reduced the vegetative growth and yield and increased the tannin content and index of total phenolic compounds. In general, Regolitic Neosols could be considered the most promising soil for producing wines of high quality.
}

Key words: leaf water potential, productivity, enological quality, enological identity. 


\section{INTRODUÇÃO}

Dentro do contexto de desenvolvimento de uma região vitícola, o clima e o solo são elementos de fundamental importância na qualidade da uva, principalmente na qualidade enológica. Atuam sobre o crescimento e a produção de videiras através de seus principais elementos: radiação solar, temperatura, umidade, precipitaçôes pluviais, textura, nutrição, entre outros (Muluins et al., 1992). As características da uva e do vinho resultam da interaçáo de diversos fatores naturais, biológicos, agronômicos e enológicos. Através de variáveis agronômicas, como a arquitetura da planta, o manejo do solo e fitossanitário, e variáveis enológicas, tais como o tipo de vinificação, pode-se aprimorar a qualidade do vinho de uma região (WAMPLE et al., 2005).

Para Bodin e Morlat (2006), a aplicação dos conceitos de indicação de procedência e denominação de origem requerem aprofundamento das características climáticas e pedológicas, onde a água representa grande importância no sistema solo-planta-atmosfera. A condição hídrica da videira é um importante fator para a definição da qualidade enológica, e moderados déficits hídricos estão associados a altos teores de tanino e antocianinas em uvas tintas (Van Leeuwen e Seguin, 1994). Desta forma, regiôes com menores precipitaçóes pluviais ou déficits hídricos controlados têm a possibilidade de aumentar a concentração de compostos desejáveis, diminuindo o teor de água nas bagas.

A utilização do potencial da água na folha, que pode ser medido com uma câmara de pressão, tem permitido estabelecer referenciais de qualidade enológica em outros países de renome vitícola, como a França e os Estados Unidos (OJeda et al., 2005; Wample et al., 2005). Contudo, no Brasil, trabalhos com este nível de detalhamento ainda não foram realizados. Nesses países, este método tem sido progressivamente adotado pelas vinícolas como uma ferramenta confiável para a determinação das práticas de manejo, distintas em subáreas do vinhedo ou entre vinhedos, proporcionando incrementos de qualidade (OJEDA et al., 2005). O detalhamento de patamares limites de potenciais da água na folha tem sido usado como estratégia de manejo da irrigaçáo, visando gerar vinhos de melhor qualidade em determinados tipos de solo, e tem sido importante como ferramenta na escolha da relação mais promissora entre eventos da dinâmica do estresse hídrico e sabor/aroma do vinho (SANTOS e KaYE, 2009).
A hipótese estabelecida no presente trabalho foi que o tipo de solo interfere na qualidade enológica, pois modifica a condição hídrica da planta. Desta forma, o trabalho teve por objetivo avaliar as relações hídricas, o crescimento e os aspectos qualitativos e quantitativos do rendimento de videiras Cabernet Sauvignon em três diferentes condiçôes de solo (Argissolo Bruno-acizentado, Planossolo Háplico e Neossolo Regolítico) em um vinhedo da indicação de procedência (IP) "Vale dos Vinhedos", no Rio Grande do Sul, buscando indicar solos mais aptos à produção de vinhos de qualidade.

\section{MATERIAL E MÉTODOS}

O experimento foi desenvolvido em vinhedo da Vinícola Miolo (2911'09'S 5134'57'W, 644 m altitude), no município de Bento Gonçalves (RS), indicação de procedência (IP) "Vale dos Vinhedos". O delineamento experimental utilizado foi em blocos casulizados tendo como tratamentos três tipos de solos (Argissolo Brunoacizentado, Planossolo Háplico e Neossolo Regolítico) e considerando cada planta uma repetição, perfazendo 10 repetiçóes por tratamento. $\mathrm{O}$ vinhedo, com sete anos de idade, era composto pela cultivar Cabernet Sauvignon sobre porta-enxerto Paulsen 1.103, conduzido em sistema espaldeira com espaçamento de 2,5 m entre linhas e 1,3 $\mathrm{m}$ entre plantas. Por haver três condições distintas de solo, o vinhedo foi divido de acordo com a classificação pedológica (Argissolo Bruno-acizentado, Planossolo Háplico e Neossolo Regolítico). Destaca-se também que os tratos culturais e o manejo da vegetação no vinhedo foram realizados nas mesmas datas e com a mesma intensidade nos três locais com os distintos solos.

A partir do início da maturação das bagas (mudança da cor, em janeiro) até a colheita, seguindo a escala fenológica de Lorenz et al. (1995), foram realizadas coletas semanais de amostras de solo (aproximadamente $400 \mathrm{~g}$ ) nas três classes de solo, em diferentes profundidades de acordo com a análise pedológica prévia dos perfis (Tabela 1). O solo coletado foi acondicionado em latas e vedado com fita adesiva. As latas contendo solo foram pesadas e, após ficarem 72 horas em estufa à temperatura de $100^{\circ} \mathrm{C}$, foram pesadas novamente. A partir das diferenças entre a massa úmida e seca foi determinada a umidade do solo em base gravimétrica.

Tabela 1. Umidade em base gravimétrica de três tipos de solos (Argissolo, Planossolo e Neossolo) em vinhedo de cv. Cabernet Sauvignon, em diferentes profundidades dos perfis. Bento Gonçalves (RS), 2009

\begin{tabular}{|lcccccccccc|} 
& \multicolumn{3}{c}{ Argissolo } & \multicolumn{3}{c}{ Planossolo } & \multicolumn{3}{c}{ Neossolo } \\
\hline Prof. (cm) & $0-24$ & $24-61$ & $61-100$ & $0-20$ & $20-40$ & $40-60$ & $0-20$ & $20-40$ & $40-60$ \\
\hline Média (\%) & 14,41 & 17,38 & 15,62 & 17,27 & 20,29 & 19,20 & 10,08 & 11,83 & 14,77 \\
\hline DP (\%) & 1,84 & 1,18 & 1,99 & 3,14 & 2,24 & 1,55 & 5,66 & 2,89 & 3,78
\end{tabular}

DP - Desvio-padrăo. 
Foram realizadas cinco mediçóes, ao longo do dia, do potencial da água na folha (MPa), em 10 folhas opostas aos cachos, coletadas aleatoriamente em cada tipo de solo (Argissolo, Planossolo e Neossolo), através de uma câmara de pressão (Sholander et al., 1965), em 3/2/2009, $10 / 2 / 2009$ e 17/2/2009. Estas medições foram realizadas às $4 \mathrm{~h}$ (antes do amanhecer), $8 \mathrm{~h}, 10 \mathrm{~h}, 12 \mathrm{~h}$ e $14 \mathrm{~h}$.

Para caracterizar o crescimento de ramos do ano foi realizada uma coleta, no estádio fenológico 81 (quando $70 \%$ dos cachos estavam no estádio de mudança de cor - escala fenológica de Lorenz et al., 1995), em 10 ramos por área, de forma aleatoria (um ramo por planta), em plantas que não foram submetidas às avaliaçôes de rendimento. A porção mediana de cada ramo foi cortada (com quatro gemas e três entrenós) e submetida à pesagem e avaliação do diâmetro e comprimento de entrenós, com paquímetro digital (marca Digimess).

No período de mudança de cor das bagas (quando a maioria dos cachos estava no estádio de mudança de cor, 81 - escala de Lorenz et al., 1995), foram coletadas aleatoriamente 200 folhas nas três condiçôes de solo (Argissolo, Planossolo e Neossolo), as quais foram individualmente pesadas, e mensurado o comprimento das duas nervuras secundárias do limbo foliar. A partir da soma do comprimento destas nervuras e da área foliar total de cada folha, utilizando-se um medidor de área foliar (marca Licor; modelo Li - 3000), foram ajustadas as equaçôes de regressão entre a soma do comprimento das nervuras e a área foliar. Em 10 plantas de cada tipo de solo foi contato o número total de folhas e foram selecionadas aleatoriamente 50 folhas para medição da soma do comprimento das nervuras. A partir de um valor médio de comprimento de nervura das 50 folhas e do número total de folhas estimou-se a área foliar de cada planta.

Na safra 2009 (6/3/09), em delineamento completamente casualizado, foram selecionadas aleatoriamente e identificadas 10 plantas em cada área (Argissolo, Planossolo e Neossolo). Toda a produção das 10 plantas de cada área foi colhida e levada para o laboratório, onde foram determinadas variáveis e componentes do rendimento: produçáo por planta, produçáo por hectare, número de cachos por planta, cachos por metro quadrado, massa e comprimento de cacho, massa de engaço, número de bagas por cacho e diâmetro transversal de bagas. Em todas estas avaliaçóes, foi utilizada balança digital (marca Deltarange; modelo Mettler PC 4400) e paquímetro digital (marca Digimess).

Foram coletadas 200 bagas aleatoriamente em cada tipo de solo (Argissolo, Planossolo e Neossolo) no dia da colheita (6/3/09). As uvas foram encaminhadas imediatamente ao laboratório, onde foram separadas manualmente as películas e as sementes, obtendo-se um lote de películas e outro de sementes, sendo as polpas descartadas. Cada lote foi pesado e as sementes foram contadas e pesadas. Pela diferença de massa entre película e semente foi es- tabelecida a relação entre película e polpa. Após, foram obtidas soluções das películas e das sementes e analisadas por cromatografia líquida de alta performance (CLAE), de acordo com método descrito por Guerra (1997).

Os dados obtidos de crescimento vegetativo, componentes do rendimento e compostos fenólicos foram sumetidos à análise estatística de variância ANOVA, e as médias comparadas pelo teste de Tukey, a 5\% de probabilidade de erro.

\section{RESULTADOS E DISCUSSÃO}

$\mathrm{Na}$ caraterização da disponibilidade hídrica dos solos avaliados foi observado que o Planossolo possui maiores percentuais de umidade em base gravimétrica, com médias de $17 \%, 20 \%$ e $19 \%$, para as profundidades de 0-20, 20-40 e 40-60 cm, respectivamente (Tabela 1). Este solo se localiza em uma área mais baixa do vinhedo que, pelas características físicas do solo, justifica os maiores percentuais de umidade em base gravimétrica. Já o Argissolo se posiciona em uma condição intermediária, e atingiu percentuais médios de $14 \%, 17 \%$ e $16 \%$, nas profundidades de 0-24, 24-61 e 61 $100 \mathrm{~cm}$ respectivamente. $\mathrm{O}$ solo com menor umidade em base gravimétrica foi o Neossolo, com percentuais médios de $10 \%, 12 \%$ e $15 \%$, nas profundidades de $0-20,20-40$ e 40-60, respectivamente (Tabela 1). Os dados de umidade (Tabela 1) evidenciaram diferenças nas características físicas dos três solos avaliados, em particular os maiores teores de areia nas primeiras camadas do neosolo, que se caracteriza como franco argilo-arenoso. Desta maneira, seus percentuais de umidade nos primeiros horizontes foram inferiores ao Argissolo e ao Planossolo (Tabela 1).

Sabe-se que o decréscimo na disponibilidade de água no solo ocasiona queda no potencial da água na folha, diminuindo a turgidez celular e a condutância estomática (Shalhevet, 1993; Ojeda et al., 2005) e também reduzindo a transpiração (CHAVARRIA et al., 2008). Nas plantas cultivadas em Argissolo e Planossolo ocorreram potenciais da água na folha significativamente superiores àquelas no Neossolo, em diversos horários dos três dias avaliados, no período da maturação das uvas (Figura 1). $\mathrm{Na}$ avaliação feita em 3/2/2009, os potenciais da água na folha só foram significativamente maiores no Argissolo e no Planossolo que no Neossolo às $14 \mathrm{~h}$, considerado de menor potencial (mais negativo) em função de ser o horário de maior demanda evaporativa ao longo do dia (Figura 1). Em 10/2/2009 foram observadas diferenças significativas nos horários de $8 \mathrm{~h}, 12 \mathrm{~h}$ e $14 \mathrm{~h}$ (Figura 1b). Todavia, não foram observadas diferenças significativas entre os potencias do Argissolo e do Planossolo, indicando que, mesmo havendo variaçáo entre as características destes solos, estas parecem não interferir no aporte hídrico às plantas ao ponto de influenciar o potencial da água na folha. 


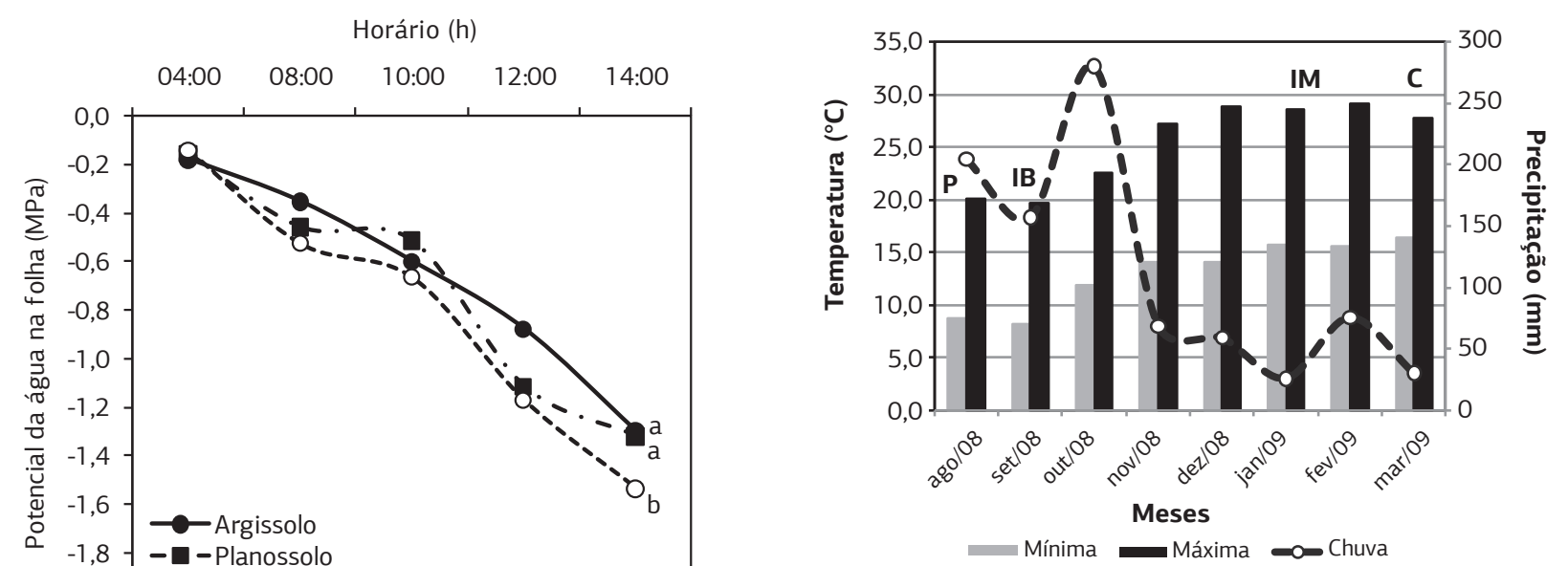

Figura 2. Temperatura máxima, mínima e precipitação pluvial ocorrida do período da poda até a colheita no Município de Bento Gonçalves localidade "Vale dos Vinhedos”. Bento Gonçalves, 2009. $\mathrm{P}$ - poda; IB - início de brotação; IM - início de maturação e C - colheita.

ao Argissolo e Planossolo. Já em 10 e 17/2/2009 foram observadas diferenças significativas em mais horários ao longo dos dias avaliados, sempre com potenciais inferiores no Neossolo (Figuras 1b e 2c).

Em ambas as avaliaçóes do potencial de base, medido antes do amanhecer, não houve diferença significativa entre plantas dos três tipos de solos avaliados (Figuras 1a, $2 \mathrm{~b}, \mathrm{c})$. Este potencial é considerado o ponto de equilíbrio entre o solo e a planta (Mullins et al., 1992). Os potenciais dos três solos adequados para o crescimento e desenvolvimento da videira, segundo OJEDA et al. (2002). Contudo, para o incremento da qualidade enológica, o potencial de base deveria se situar na faixa de $-0,2$ a - 0,6 $\mathrm{MPa}$, no período de maturação (OJEDA et al., 2002) e ele ficou acima de -0,2 MPa em todos os casos avaliados (Figura 1). Tal constatação sobre a ausência de restrição hídrica para incremento da qualidade enológica, na Serra Gaúcha, foi observada também por Chavarria et al. (2008), através do potencial da água na folha medido na cultivar Moscato Giallo.

O conhecimento dos níveis de potencial da água na folha é fundamental para a busca da qualidade enológica, uma vez que o balanço hídrico da videira tem influência direta sobre a composição da baga, principalmente no teor de açúcar, na acidez (ácido málico e tartárico) e nos compostos fenólicos (taninos, antocianinas, flavonóides, etc.) (Choné et al., 2001; Kennedy et al., 2000; OJedA et al., 2005).

As videiras cultivadas no Argissolo possuem ramos mais pesados e com diâmetro superior às cultivadas em Planossolo e Neossolo, também as folhas são de maior comprimento de nervuras e maior área foliar por planta (Tabela 2). De acordo com estes resultados, pode-se inferir que, comparando os três solos estudados, as condiçóes propiciadas pelo Argissolo são mais favoráveis ao crescimento vegetativo da videira. 
De forma geral, as videiras do Neossolo têm crescimento vegetativo inferior, comparativamente aos demais solos (Tabela 2). Este comportamento pode ser atribuído à menor disponibilidade de água nesse solo. Sabe-se que o diâmetro do tronco é um indicador das condiçôes de vigor das plantas. E na avaliação deste parâmetro não foram observadas diferenças entre as videiras cultivadas nos três tipos de solo.

Os ramos das videiras do Neossolo possuem valores de massa, diâmetro e comprimento de entrenós significativamente inferiores comparativamente ao Argissolo e planossolo (Tabela 2). Estas mesmas diferenças ocorreram no enfolhamento, tanto pelo menor comprimento das nervuras das folhas como pela menor área foliar (Tabela 2). Estes parâmetros de crescimento do dossel vegetativo enfatizam o efeito da restrição hídrica sobre o crescimento das plantas no Neossolo.

A produção por planta e por área das videiras cultivadas no Planossolo maior que no Argissolo e no Neossolo (Tabela 3). A maior produtividade do Planossolo pode estar associada à maior disponibilidade hídrica para as plantas e, consequentemente, melhores condiçôes para o ganho em produtividade.
O maior conteúdo de água nas bagas também propiciou cachos mais pesados. Nos cachos oriundos de videiras do Neossolo houve menor massa e comprimento, comparativamente aos demais solos estudados (Tabela 4). Esta redução está associada somente ao menor número de bagas, pois a massa individual de bagas foi similar entre os dois tipos de solo (Tabela 4). Estes indicadores do crescimento do cacho revelam que a restrição hídrica, que afetou o desenvolvimento vegetativo, também afetou os cachos.

Embora nas bagas das videiras do Neossolo os valores de diâmetro transversal tenham sido significativamente inferiores, não foram observadas diferenças significativas na relação entre película e polpa das bagas (Tabela 4). Este parâmetro está associado à qualidade enológica da uva, pois quanto maior for esta relação maior será o conteúdo de elementos que imprimem qualidade ao vinho, como por exemplo, os compostos fenólicos (SiLVA et al., 2008).

As antocianinas na película das bagas não tiveram variação em função do tipo de solo estudado (Tabela 5). Segundo Freeman e Kliewer (1983), o estresse hídrico poder causar incremento de até $44 \%$ no teor de antocianinas nas bagas. Alguns trabalhos destacam que o incremento de antocianinas por restrição hídrica ocorre pela

Tabela 2. Parâmetros do crescimento vegetativo de videiras cv. Cabernet Sauvignon, em vinhedo cultivado em três tipos de solo (Argissolo, Planossolo e Neossolo) na Indicação de Procedência (IP) Vale dos Vinhedos, na colheita. Bento Gonçalves (RS), 2009

\begin{tabular}{|c|c|c|c|c|c|c|}
\hline \multirow{3}{*}{$\begin{array}{l}\text { Tipos de } \\
\text { solos }\end{array}$} & \multirow{2}{*}{$\begin{array}{c}\text { Tronco } \\
\text { Diâmetro }\end{array}$} & \multicolumn{3}{|c|}{ Ramos } & \multicolumn{2}{|c|}{ Folhas } \\
\hline & & $\begin{array}{c}\text { Massa de } \\
\text { ramos }\end{array}$ & Diâmetro & $\begin{array}{l}\text { Comprimento } \\
\text { de entrenós }\end{array}$ & $\begin{array}{l}\text { Comprimento } \\
\text { de nervuras }\end{array}$ & Área foliar \\
\hline & $\mathrm{mm}$ & g & $\mathrm{mm}$ & $\mathrm{cm}$ & $\mathrm{cm}$ & $\mathrm{cm}^{2}$ \\
\hline Argissolo & $34,02 a$ & $37,09 a$ & $10,18 a$ & $10,56 a$ & $10,47 a$ & $158,15 a$ \\
\hline Planossolo & $33,61 a$ & $30,54 b$ & $8,96 b$ & $10,72 a$ & $9,74 b$ & $139,37 a$ \\
\hline Neossolo & $31,24 a$ & $18,26 c$ & $7,59 c$ & $8,84 b$ & $9,65 b$ & $123,79 b$ \\
\hline
\end{tabular}

Letras distintas na coluna representam diferença significativa ao nível de $5 \%$ de probabilidade de erro, pelo teste de Tukey.

Tabela 3. Componentes do rendimento de videiras, cv. Cabernet Sauvignon, em vinhedo cultivado em três tipos de solo (Argissolo, Planossolo e Neossolo) na Indicação de Procedência (IP) Vale dos Vinhedos, na colheita. Bento Gonçalves (RS), 2009

\begin{tabular}{|c|c|c|c|c|c|}
\hline $\begin{array}{l}\text { Tipos de } \\
\text { solo }\end{array}$ & $\begin{array}{c}\text { Produção por planta } \\
\text { kg }\end{array}$ & $\begin{array}{c}\text { Produção por hectare } \\
\mathbf{t}\end{array}$ & $\begin{array}{c}\text { Cachos por planta } \\
\text { un. }\end{array}$ & $\begin{array}{c}\text { Cachos por } \mathrm{m}^{2} \\
\text { un. }\end{array}$ & $\begin{array}{c}\text { Ramos por } \mathbf{m}^{2} \\
\text { un. }\end{array}$ \\
\hline Argissolo & $3,44 b$ & $10,5 b$ & $15,9 a$ & $4,89 a$ & $12,6 b$ \\
\hline Planossolo & $4,86 a$ & $14,97 a$ & $12,3 b$ & $3,78 b$ & $12,9 b$ \\
\hline Neossolo & $3,58 b$ & $11,03 b$ & $12,5 b$ & $3,85 b$ & $17 a$ \\
\hline
\end{tabular}

Letras distintas na coluna representam diferença significativa ao nível de $5 \%$ de probabilidade de erro, pelo teste de Tukey.

Tabela 4. Características de cachos de videiras, cv. Cabernet Sauvignon, em vinhedo cultivado em três tipos de solo (Argissolo, Planossolo e Neossolo) na Indicação de Procedência (IP) Vale dos Vinhedos, na colheita. Bento Gonçalves (RS), 2009

\begin{tabular}{lcccccccc} 
Tipo de solo & Massa & $\begin{array}{c}\text { Número de } \\
\text { bagas }\end{array}$ & $\begin{array}{c}\text { Massa de } \\
\text { baga }\end{array}$ & $\begin{array}{c}\text { Comprimento } \\
\text { de cachos }\end{array}$ & $\begin{array}{c}\text { Massa do } \\
\text { ráquis }\end{array}$ & $\begin{array}{c}\text { Relação } \\
\text { película/polpa }\end{array}$ & $\begin{array}{c}\text { Diâmetro de } \\
\text { baga }\end{array}$ \\
\hline Argissolo & $\mathbf{g}$ & un. & $\mathbf{g}$ & $\mathbf{c m}$ & $\mathbf{g}$ & $10,98 \mathrm{a}$ & $0,52 \mathrm{a}$ & $14,50 \mathrm{a}$ \\
\hline Planossolo & $251,50 \mathrm{a}$ & $161,70 \mathrm{a}$ & $1,46 \mathrm{a}$ & $15,05 \mathrm{a}$ & $10,50 \mathrm{a}$ & $14,29 \mathrm{a}$ \\
\hline Neossolo & $242,35 \mathrm{a}$ & $139,70 \mathrm{~b}$ & $1,65 \mathrm{a}$ & $14,50 \mathrm{a}$ & $10,66 \mathrm{a}$ & $0,49 \mathrm{a}$ & $0,45 \mathrm{a}$ & $13,66 \mathrm{~b}$ \\
\hline
\end{tabular}

Letras distintas na coluna representam diferença significativa ao nível de $5 \%$ de probabilidade de erro, pelo teste de Tukey. 
Tabela 5. Compostos fenólicos na película e na semente de uvas Cabernet Sauvignon, em vinhedo cultivado em três tipos de solo (Argissolo, Planossolo e Neossolo) na Indicação de Procedência (IP) Vale dos Vinhedos, na colheita. Bento Gonçalves (RS), 2009

\begin{tabular}{|c|c|c|c|c|}
\hline \multirow{4}{*}{ Tipo de solo } & \multicolumn{4}{|c|}{ Compostos fenólicos } \\
\hline & \multicolumn{2}{|c|}{ Película } & \multirow{2}{*}{$\begin{array}{c}\text { Sementes } \\
\text { Taninos }\end{array}$} & \multirow{3}{*}{$\begin{array}{l}\text { Película e sementes } \\
\qquad \text { IPT * }\end{array}$} \\
\hline & Antocianinas & Taninos & & \\
\hline & mg L-1 & \multicolumn{2}{|c|}{$\mathrm{g} \mathrm{L}^{-1}$} & \\
\hline Argissolo & $618,34 a$ & $0,81 b$ & $1,60 c$ & $15,17 c$ \\
\hline Planossolo & $593,7 a$ & $1,39 a$ & $5,76 b$ & $30,57 b$ \\
\hline Neossolo & $611,48 a$ & $1,60 a$ & $8,94 a$ & $37,37 a$ \\
\hline
\end{tabular}

Letras distintas na coluna representam diferença significativa de $5 \%$ de probabilidade de erro, pelo teste de Tukey. * IPT - Índice de polifenóis totais.

redução no tamanho da baga, aumentando a proporção de película (Kennedy et al., 2002; OJeda et al., 2005). Neste contexto, esperava-se que a restriçăo hídrica, promovida pelo Neossolo, pudesse causar incremento nas antocianinas, como causou na redução do tamanho da baga. Porém, possivelmente esta restrição não tenha sido suficiente para causar tais efeitos, pois no período estudado ocorreram diversos eventos de chuva ao longo da maturação (Figura 2).

Por outro lado, nos taninos foram observadas diferenças significativas, destacando-se maiores teores de tanino nas uvas produzidas no Neossolo, sobretudo nas sementes (Tabela 5), cujas plantas foram submetidas à maior restrição hídrica. Este é um dos fatores de maior relevância para a obtençáo de uvas com elevado potencial enológico (OJEDA et al., 2005).

Os compostos derivados do metabolismo secundário são mais benéficos à qualidade enológica e responsáveis por características peculiares do vinho, imprimindo identidade do produto final com a região na qual foi elaborado. Dentre estes compostos, destacam-se os fenólicos, que são caracterizados por possuirem um anel aromático com um ou mais substituintes hidroxílicos, incluindo seus grupos funcionais (ShaHidi e NACZK, 1995). Dentre as frutas, a uva é uma das maiores fontes destes compostos. Nesta espécie os principais compostos fenólicos presentes são os flavonóides (antocianinas e flavanóis), os estilbenos (resveratrol), os ácidos fenólicos (derivados dos ácidos cinâmicos e benzóicos) e uma larga variedade de taninos (Francis, 2000).

O índice de polifenóis totais (IPT) extraídos da película e sementes teve também incremento significativo nas uvas provenientes do Neossolo (Tabela 5), corroborando com o padrão observado nos taninos. Todavia, segundo Hernández (2004), o IPT observado nos vinhos do Argissolo não seria capaz de produzir vinhos de excelência, somente no Planossolo, e, sobretudo, no Neossolo, que atingiu valores significativamente superiores (Tabela 5), pois, segundo este autor, vinhos com valores de IPT menores de 30 são de qualidade inferior.

As formas mais eficientes de aumento do IPT, através da biossíntese, estão associadas à sanidade das uvas e ao déficit hídrico. Segundo SiLva et al. (2008), um dos siste- mas de defesa das plantas contra agentes fitopatógenos é a síntese de substâncias fungistáticas, incluindo polifenóis. Compostos fenólicos com atividade antimicrobiana são os taninos e o ácido tânico (Beuchat, 2001), e o aumento na incidência de doenças pode causar maiores concentraçôes de taninos e, consequentemente, de IPT. Contudo, no presente trabalho não houve diferenças na incidência de doenças fúngicas nos cachos, pois foram efetivamente controladas. Desta maneira, estes incrementos em taninos e IPT (Tabela 5) podem ser atribuídos à restrição hídrica, que ocorreu com maior intensidade no Neossolo.

\section{CONCLUSÃO}

Dentre os solos estudados, o Neossolo Regolítico é o mais promissor para a obtenção de vinhos finos de qualidade na Indicação de Procedência "Vale dos Vinhedos".

Argissolos Bruno-Acizentados propiciam maior crescimento vegetativo de videiras, sobretudo em massa de ramos, comprimento de entrenós e área foliar. Os cachos das videiras cultivadas neste solo também possuem maior número de bagas.

Planossolos Háplicos têm maior disponibilidade hídrica, favorecendo a maior produtividade das videiras em relação aos demais solos.

Neossolos Regolíticos possuem menor disponibilidade hídrica, que reflete na redução do potencial da água na folha. Com restrição hídrica observam-se nas videiras menor crescimento e rendimento, e maiores teores de taninos e índice de polifenóis totais.

\section{REFERÊNCIAS}

BEUCHAT, L.R. Control of foodborne pathogens and spoilage microorganisms by naturally occurring antimicrobials. In: WILSON, C.L.; DROBY, S. (Ed.). Microbial food contamination. Boca Raton: CRC Press, 2001. p.149-169.

BODIN, F; MORLAT, R. Characterization of viticultural terroirs using a simple field model based on soil depth I. Validation of the water supply regime, phenology and vine vigour, in the anjou vineyard (France). Plant and Soil, v.281, p.37-54, 2006. 
CHAVARRIA, G.; SANTOS, H.P.; FELIPPETO, J.; MARODIN, G.A.B.; BERGAMASCHI, H.; CARDOSO, L.S.; FIALHO, F.B. Relaçôes hídricas e trocas gasosas em vinhedo sob cobertura plástica. Revista Brasileira de Fruticultura, v.30, p.1022-1029, 2008.

CHONÉ, X.; LEEUWEN, C.; DUBOURDIEU, D.; GAUDILLÈRE, J.P. Stem water potential is sensitive indicator of grapevine water status. Annals of Botany, v.87, p.477-483, 2001.

FRANCIS, F.J. Anthocyanins and betalains: composition and applications. Cereal Foods World, v.45, p.208-213, 2000.

FREEMAN, B.M.; KLIEWER, W.M. Effect of Irrigation, Crop Level and Potassium Fertilization on Carignane Vines. II: Grape and wine quality. American Journal of Enology and Viticulture, v.34, p.197-207, 1983.

GUERRA, C. C. Recherches sur les interactions anthocyanesflavanols: application à l'interprétation chimique de la couleur des vins rouges. 1997. Doutorado (Sciences Biologiques et Medicales) Université Victor Segalen Bordeaux II, Bordeaux, 1997.

HERNÁNDEZ, M.R. Medida del color de la uva y del vino y los polifenoles por espectrofotometría. In: Curso de Viticultura para Aficionados en 20 lecciones. Haro: La Rioja, 2004.

KENNEDY, J.A.; MATTHEWS, M.A.; WATERHOUSE, A.L. Effect of Maturity and Vine Water Status on Grape Skin and Wine Flavonoids. American Journal of Enology and Viticulture, v.53, p.268-274, 2002.

KENNEDY, J.A.; TROUP, G.J; PILBROW, J.R.; HUTTON, D.R.; HEWITT, D.; HUNTER, C.R; RISTIC, R.; ILAND, P.G.; JONES, G.P. Development of seed polyphenols in berries from Vitis vinifera L. cv. Shiraz. Australian Journal of Grape and Wine Research, v.6, p.244-254, 2000.

LORENZ, D.H.; EICHORN, K.W.; BLEHOLDER, H.; KLOSE, R.; MEIER, U.; WEBER, E. Phenological growth stages of grapevine (Vitis vinifera L.): Codes and descriptions according to the extended BBCH scale. Australian Journal of Grape and Wine Research, v.1, p.100-103, 1995.

MULLINS M.G.; BOUQUET A.; WILLIAMS L.E. Biology of the grapevine. New York: Cambridge University, 1992. 239p.
OJEDA, H.; ANDARY, C.; KRAEVA, E.; CARBONNEAU, A.; DELOIRE, A. Influence of pre and postveraison water deficit on synthesis and concentration of skin phenolic compounds during berry growth of Vitis vinifera L., cv. Shiraz. American Journal of Enology and Viticulture, v.53, p.261-267, 2002.

OJEDA, H.; CARILLO, N.; DEIS, L.;TISSEYRE, B.; HEYWANG, M.; CARBONNEAU, A. Viticulture de précision et état hydrique. II: Comportement quantitatif et qualitatif de zones intraparcellaires définies à partir de la cartographie des potentiels hydriques. In : Journées GESCO, 24., 2005, Geisenheim, Allemagne. Annales... Geisenheim, 2005. p.741-748.

SANTOS, A.O.; KAYE, O. Composição quali-quantitativa da produção de 'Syrah' cultivada sob estresse hídrico transiente. Revista Brasileira de Engenharia Agrícola e Ambiental, v.13, p.272281, 2009.

SCHOLANDER, P.F.; HAMMEL, H.T.; BRADSTREET, E.D.; HEMMINGSEN, E.A. Sap pressure in vascular plants. Science, v.148, p.339-347, 1965.

SHAHIDI, F.; NACZK, M. Food Phenolics: sources, chemistry, effects and applications. Lancaster: Technomic, 1995, 331p.

SHALHEVET, J. Plants under salt and water stress. In: FOWDEN, L.; MANSFIELD, T.; S TODDART, J. (Ed.). Plant adaptation to environmental stress. London: Champman e Hall, 1993. p.133-154.

SILVA,L.C.; KRETZSCHMAR,A.A.; RUFATO,L.;BRIGHENTI, A.F.; SCHLEMPER, C. Níveis de produção em vinhedos de altitude da cv. Malbec e seus efeitos sobre os compostos fenólicos. Revista Brasileira de Fruticultura, v.30, p.675-680, 2008.

VAN LEEUWEN, C.; SEGUIN, G. Incidences de l'alimentation en eau de la vigne, appréciée par l'état hydrique du feuillage, sur le développement de l'appareil végétatif et la maturation du raisin (Vitis vinifera Variété Cabernet Franc, Saint-Emilion 1990). Journal International des Sciences de la Vigne et du Vin, v.28, p.81-110, 1994.

WAMPLE, R.L.; WILLIANS, L.; ADAMS, D. Wine grape irrigation management in the San Joaquin Valley of California. In: CURSO INTERNATIONAL MANEJO DE RIEGO Y SUELO EN VIDES PARA VINO Y MESA, October, Santiago de Chile, 2005, p.38-46. 